\title{
ANALYSIS OF DELAYS AND EXTENSION OF EXECUTION DURATION OF A ROAD PROJECT
}

Mirela Mădălina STOIAN, Associate Prof., PhD, Technical University of Civil Engineering Bucharest, e-mail: mada.stoian62@yahoo.com

Mihai DICU, Professor, PhD, Technical University of Civil Engineering Bucharest, e-mail: mdicu5@yahoo.com

\section{Rezumat}

La execuţia proiectelor de infrastructură rutieră se înregistrează adesea întârzieri, datorită unor cauze obiective, cu repercursiuni asupra termenului final de execuție și cu implicații valorice. Utilizarea metodei drumului critic pentru planificare și a ferestrelor de execuție, va avea ca efect o mai bună gestionare a timpilor proceselor și o optimizare a întârzierilor.

Cuvinte cheie: infrastructură, planificare, întarziere, drum critic.

\section{Abstract}

The implementation of road infrastructure projects often results in delays due to objective causes, with repercussions on the final execution deadline and with value implications. The use of critical path method for planning and the executin windows, will result in better time process management and optimization delays.

Keywords: infrastructure, contract, critical path, planning, delay.

\section{GENERAL CONSIDERATIONS}

This article aims to highlight an efficient monitoring procedure of execution of works, exemplified on a project of modernization of a road infrastructure. In order to follow the execution of the contracted execution schedule, there are various working methods, some of them assisted by specialized computing programs, which allow ensuring some correlations between the activities scheduled to be executed, observing the contracted execution term.

Several responsible factors are involved in fulfilling a construction project, such as the Beneficiary, the Consultant Engineer, the Site Supervisor 
Engineer, the Contractor and the Sub-Contractors with the Technical Expert in Charge with Execution, as well as the state control institutions, respectively the State Inspection in Construction. However, the direct responsibility for achieving the construction objective lies with the Beneficiary and the Contractor, through their representatives responsible for direct execution

We can assist in unforeseen situations at the time of contracting with respect to the Execution Chart accompanied by the detailed Work Program that cannot be applied precisely due to: some details of the unfinished execution in the Construction Technical Documentation, of the endorsements and approvals that are not obtained by the Beneficiary or by the Contractor, unplanned expropriations for the Contractor's assignment of the land free of any charges, or various other causes.

In this situation, the Contractor, who has already set up a work schedule based on the contractual elements received with the Execution Order, faces a series of problems that he has to anticipate.

\section{PROJECT MANAGEMENT}

An efficient method of simulating execution tasks initially programmed in the contracted Execution Chart is to develop a Detailed Execution Chart using the Critical Path Method. This method allows for a periodic updating of Work Progress Reports, as it analyzes the implications of disruptions in execution over the entire chain of implicit activities, which can actually lead to extensions of execution deadlines for the construction object.

These time-extension of the terms needed for execution, affect the contractual clauses between the Beneficiary and the Contractor, with effects on the cash flow.

They can also cause tensions between the Beneficiary and the Contractor subject to delays that he apparently is unable to solve and for which he is compelled to keep a clear record of the execution on construction objects and to analyze variants of rescheduling the works.

One of the most important and most accepted methods of achieving this prevention objective at international level is the scientific analysis of delays that use the critical path method as a tool for assessing the relationship between "cause" and "effect. Experts, Mediators, Arbitrators and Judicial Bodies unanimously recognize the importance of the "critical path" in demonstrating "causality" in construction disputes. 
The critical path is defined as the longest sequence of activities in a project plan which must be completed on time for the project to complete on due date

Several critical paths may exist, depending on workflow logic. A delay in the evolution of any activity on the critical path will cause the overall duration of the project to be prolonged and is therefore called a "critical delay".

Critical Work Program Level of detailed work schedule for the entire work set out in the Start Report of the contract changes over time, depending on the actual situations encountered during execution, in the form of Updated Work Charts. Because of this, the Work Schedule contracted from the Project Execution Chart is divided into secondary critical paths, as opposed to using other classical methods such as bar graphs without network logic.

In the following figure there is an example of works scheduling within the Execution Chart, which represents a sequencing of the activities in a technological logic, with the durations calculated according to the productivity of the types of equipment used, in practice the resources necessary for their realization. As the productivity in execution differs from the theoretical productivity foreseen in the design, it is imperative to continuously follow up and update the Execution Charts, as the project develops, in order to justify the Work Progress Reports submitted in order to approve the Payment Certificates.

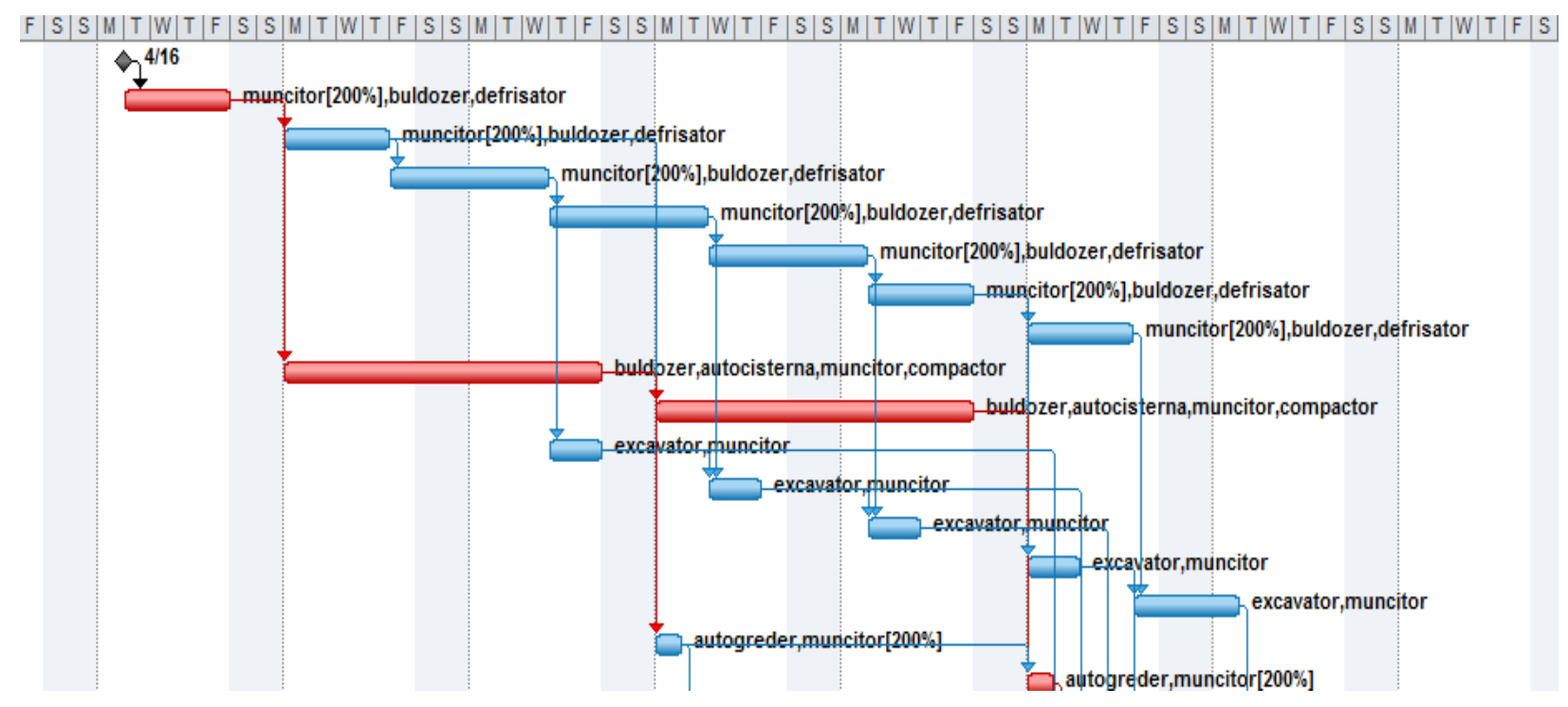

Figure 1. Gantt Chart

Proving the "link" between "cause" and "effect" of delays is the most important point of any analysis of delays. In order to establish this link in the 
Contract, the Contractor will have to prove that the works have been delayed due to situations registered and recorded in the Construction Site Communication.

He will also have to show that the delays were caused by one of the relevant events / causes he will chronologically list and that they led to the delay in finalizing the works, despite all the efforts to mitigate the negative effects he had undertaken as an Entrepreneur of the works.

The figure below shows, for example, the concept of recording an interruption of activity and the fact that an alternative is sought for the reorganizing of the operating time so as to minimize the delay of the final term of the work to the maximum.

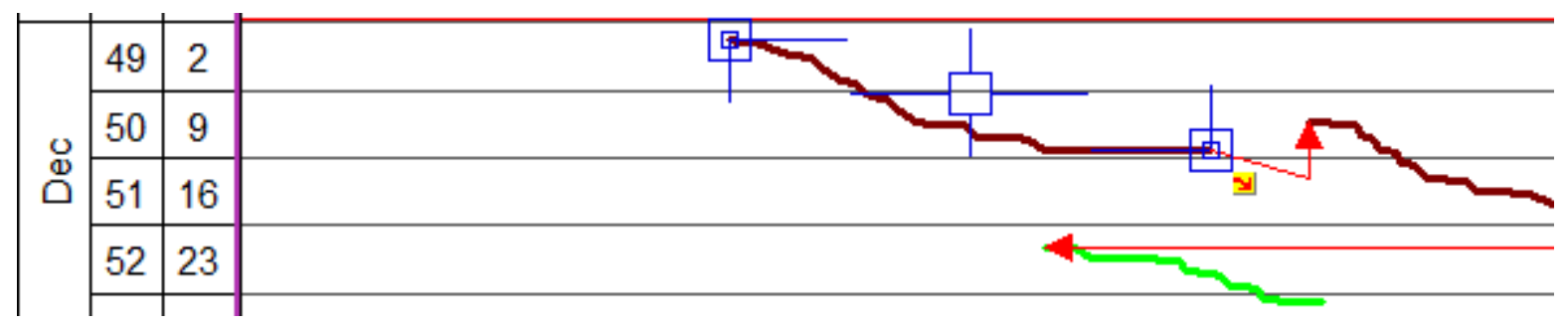

Figure 2. Alternative to reorganize activities by reducing delays

Scenarios with parallel activities are analyzed, scenarios that lead to a new reorganization of the Work Schedule within a re-updated Execution Chart.

Therefore, a new Work Schedule will be established, permanently updated, depending on the progress achieved in the project development, as well as on the delays and disturbances suffered during the execution of the works, due to events independent of the Contractor's attributions.

The Chart is elaborated through a careful Retrospective Analysis for Assessing and Identifying of Risk Generating Events for Project, in order to determine how the acts that caused delays affected the evolution of the works as the "cause" of each delays generating event.

Thus, the necessity of an extension term appears, by cumulation and it will be inserted in Works Execution Chart, as in the diagram below: 


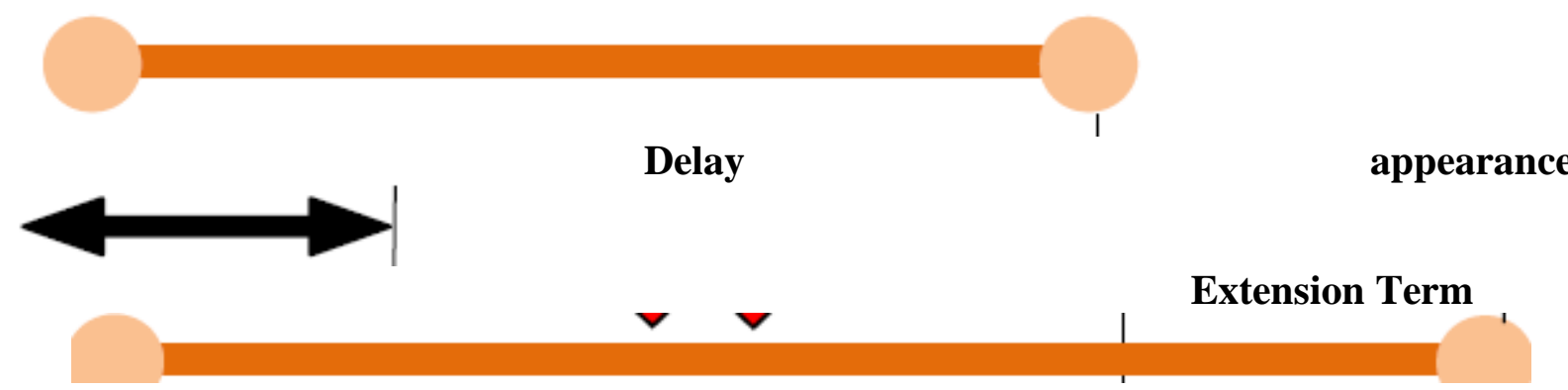

The new execution duration due to the effects of delays unexpected When the works were contracted

The justifying the effects of the events of delay claimed by the Contractor at the Beneficiary may be made using the method known as "Windows Analysis", a retrospective analysis technique of the impact on the contracted Works Chart.

In the sense of this method, a "window" represents a period of time, resulting by the division of the total duration of the construction, in less lucrative periods.

Within this framework, each new set of activities update information caused by the appearance of a disturbing element, can be inserted into the program, in each window, which may represent a distinct stage of the execution.

Once divided into identifiable periods, any analysis method can be applied to the selected "window".

Also, in the critical path algorithm, the term "margin," which represents the time available for which an activity was scheduled, in addition to its scheduled duration, should be included in the critical path computation algorithm to cover unforeseen delays, exemplified below:

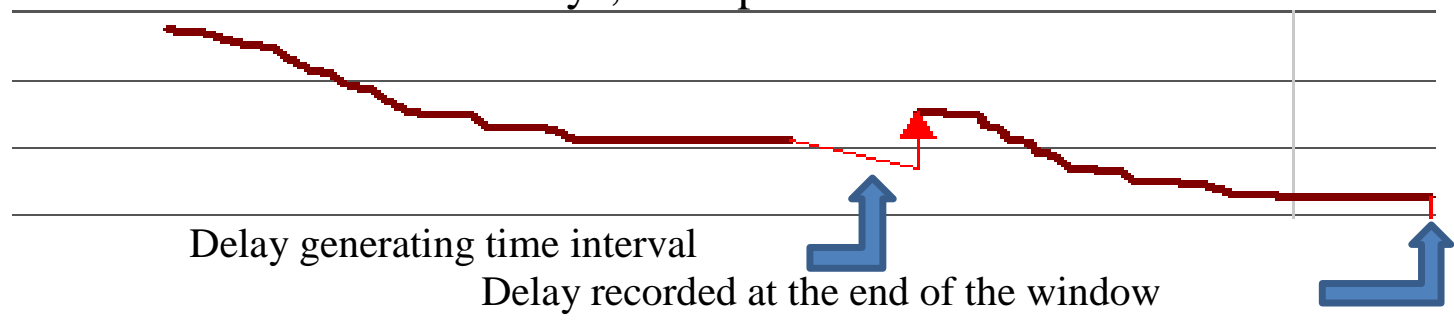

In this figure, there is a case in which a period of time, a delay occurs, that is transmitted at the end of an activity contained within a Window.

The evaluation of each justifiable and compensable delay generating event is performed and quantified cumulatively along the critical path achieved, as it 
aims at analyzing the critical path actually achieved by comparison with the critical path of the core program, namely the contracted Execution Chart.

This technique generally uses schedule updates that are correlated with the execution activities registered in the Construction Site's Logs, highlighting the justifications for each delay or modification of the initial work scheduling. In this way, it is possible to assess the impact on the achieved critical path, which is associated with the change in the Execution Chart, affected by the delay recorded in the Construction Site Log.

Windows Analysis allows you to examine the dynamics of the critical path of the works from a period to another one, as the project progresses, by evaluating the information and records in the Construction Site Log, as well as by the Site Correspondence, regarding the work done. The purpose is to determine whether delays or changes in the execution program have influenced the scheduled critical path of a project.

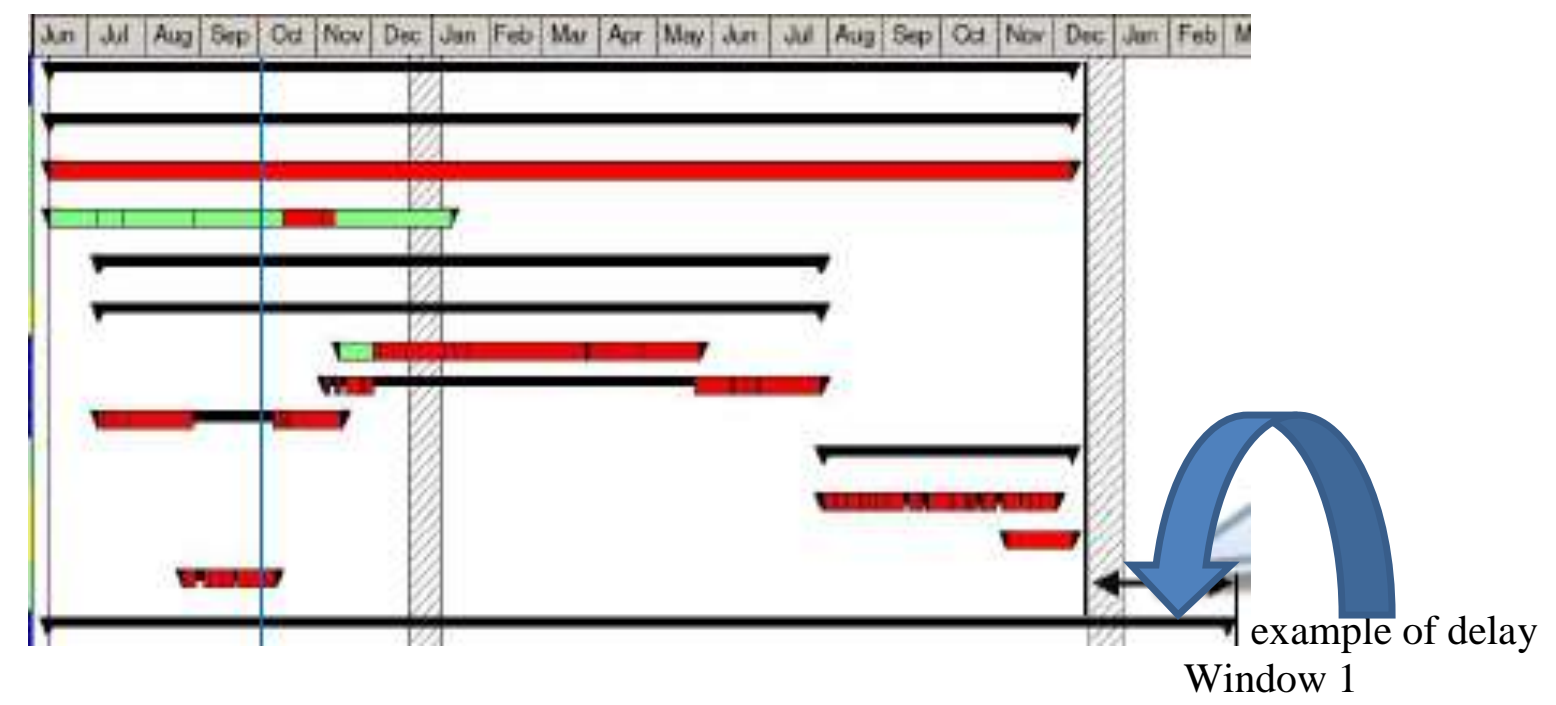

Figure 3. Gantt Chart with Delay

The Longest Path $\mathrm{s}$ defined as the longest succession of activities, between the Approved Start Date and the last activity in the program, respectively the final contracted term. 
ROMANIAN JOURNAL

OF TRANSPORT INFRASTRUCTURE

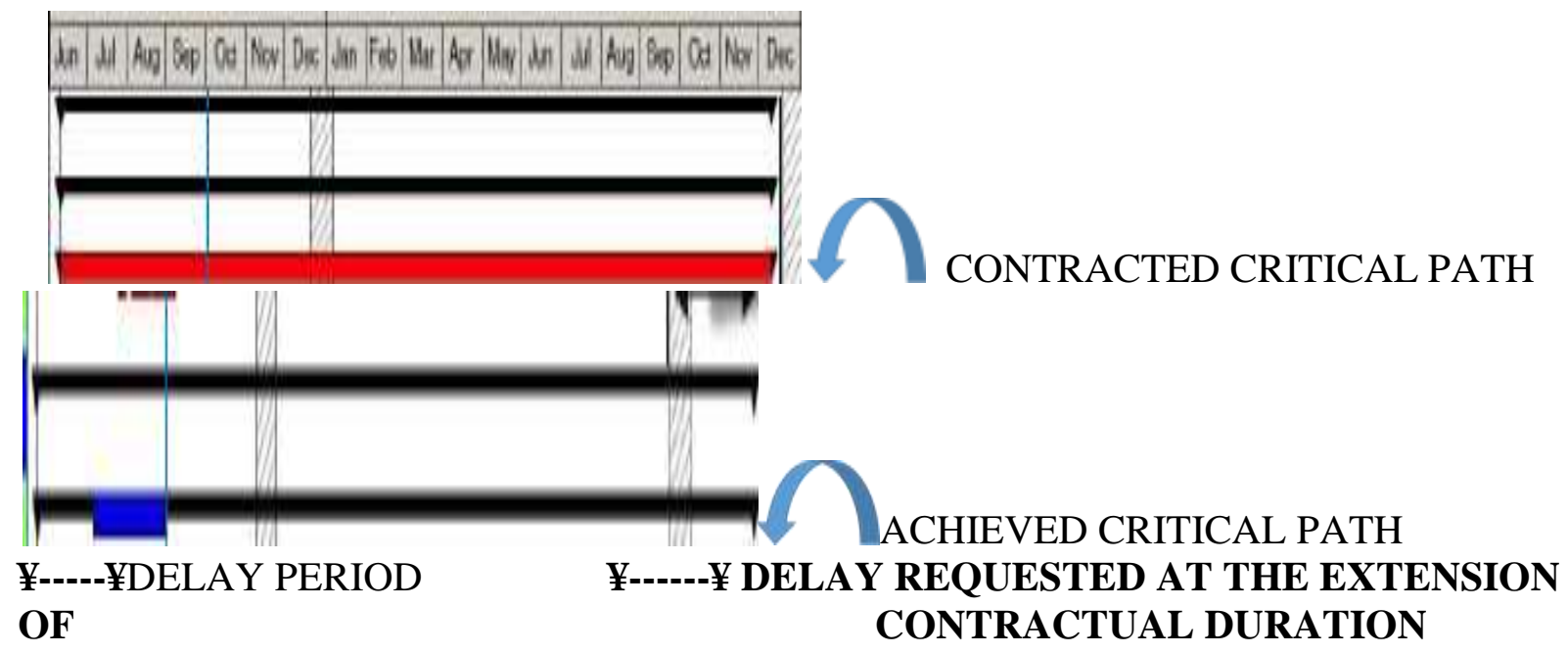

Figure 4. Comparison between critical path contracted - critical path achieved

It is important that during monitoring the execution, which defines the progress of the project, to provide "windows" (periods of time necessary to achieve distinct parts of the objective) at the level of execution details within the so-called "Works Grouping Structure" or Work Breakdown Structure.

This term is used in Project Management as a tool for defining activity groups, on distinct execution objects within a project.

For a Road Upgrading project, an example of the activities involved in the contracted Execution Chart is as follows:

\section{Detailed Initial Execution Chart}

GENERAL CONSTRUCTION SITE ORGANIZING ACTIVITIES CONSTRUCTION SITE ORGANIZATION

PREPARATORY LAND WORKS

CIRCULATION AND TRAFFIC MANAGEMENT

ENVIRONMENT PROTECTION FACILITIES

LOCAL REPAIR WORKS ON EXISTING INFRASTRUCTURE

EXECUTION OF THE NEW RUTIER SYSTEM

FINISHING WORKS FOR RESUMING THE TRAFFIC

The Detailed Execution Program includes all the activities related to the construction provided in Window 1 . If there is a disturbing factor such as delays in the application of the " PREPARATORY LAND WORKS " activity due to the lack of design details or not finalizing the expropriations in order to grant the 
land necessary to the construction site free of any charges, a cumulative delay period results.

The period of activity stagnation, due to initially unforeseen situations, affects a number of activities scheduled in the Initial Execution Chart.

By using activities durations optimization scenarios, using Critical Path computing programs, the resources are reoriented and the implicit delays resulting from the end of the Window 1 term are calculated.

\section{CONCLUSIONS}

The execution windows, considered as building object parts, may have overlapping execution periods, and the critical path will be analyzed on the project as a whole.

An optimization of the delays in all the works will be made, the final delay considered in the request for extension of the contractual term and the value recalculation of the implications of these cumulative delays, which the Contractor must benefit from.

\section{REFERENCES}

1. Szonyi, A.J., Fenton, R.G. - Principles of engineering economic analyses, Ed. Wall\&Emerson, Inc. 1989

2. Raffestin, Y., Armand, J. - Conduire son chantier, Ed. Du Moniteur, 1994 